\title{
Modelling Demand-driven Chain Networks using Multiple CODPs
}

\author{
C.N. Verdouw ${ }^{1}$, A.J.M. Beulens ${ }^{2}$, D. Bouwmeester ${ }^{2}$, and J.H. Trienekens ${ }^{3}$ \\ 1 Agricultural Economics Research Institute (LEI), Wageningen UR \\ P.O. Box 29703, 2502 LS The Hague, The Netherlands \\ WWW home page: http://www.lei.wur.nl \\ 2 Information Technology Group, Wageningen University \\ Hollandseweg 1, Wageningen, The Netherlands \\ 3 Management Studies Group, Wageningen University \\ Hollandseweg 1, Wageningen, The Netherlands
}

\begin{abstract}
.
Purpose - to model demand-driven chain networks on basis of multiple Customer Order Decoupling Points (CODPs). Design/methodology/approach - literature study and a case study in dairy industry, based on in-depth expert interviews. Findings - four main underlying factors of CODP diversity are addressed and modelled. Research limitations/implications - the proposed multiple CODP models provide the basic setup of a reference-process model for demand-driven chain networks, and should further be developed into a formalized model that incorporates detailed implementation knowledge of different industries. Practical implications - the research contributes to making the generic CODP concept suitable for process design of demand-driven chain networks. Originality/value - the paper adds to existing research on CODPs by addressing the main underlying factors of CODP diversity. Based on these dimensions, basic process models of demand-driven chain networks are proposed and applied in dairy industry. Keywords Customer Order Decoupling Point (CODP), Demand-driven chain networks, Dairy Paper type Research paper, Case study
\end{abstract}

\section{Introduction}

Demand-driven chain networks are often mentioned as a way to meet volatile customer demand and to involve customer impact in the execution of all chain processes. However, it is not easy to realize chain networks that are able to deliver customized products to specific customer needs and to fulfill new or adjusted customer requirements rapidly.

The main challenge of creating demand-driven chain networks is to realize rapid and customized response to customer demand. This requires a combination of efficiency to fulfil demand with minimal use of time and money, and flexibility to deal with the ever-changing amount and variety of the demand. In order to find a

Please use the following format when citing this chapter:

Verdouw, C.N., Beulens, A.J.M., Bouwmeester, D. and Trienekens, J.H., 2008, in IFIP International Federation for Information Processing, Volume 257, Lean Business Systems and Beyond, Tomasz Koch, ed.; (Boston: Springer), pp. 433-442. 
balance between efficiency and flexibility, the positioning of customer order decoupling points (CODPs) plays a central role (Naylor et al. 1999). The CODP separates that part of the supply chain geared towards directly satisfying customers' orders from that part of the supply chain based on planning (Hoekstra and Romme 1992). It creates the opportunity for upstream activities to optimize independently from irregularities in market demand. Upstream the focus can be on efficient production of standardized products, while downstream the focus is on flexible strategies to deliver customized products. The strategic inventory at the decoupling point is the buffer that absorbs demand variability (Naylor et al. 1999).

The position of decoupling points is a balancing process between market, inherent product properties and process related factors (Olhager 2003). Major factors are demand volume and volatility, and the relationship between required delivery times and possible production lead times (the P/D ratio, Mather 1988).

On basis of different positions of the CODP, basic logistical configurations are proposed in literature. (Hoekstra and Romme 1992) distinguish five configurations: engineer-to-order (ETO), make-to-order (MTO), assemble-to-order (ATO), make-tostock (MTS) and deliver from (local) stock (DFS). However, this typology is at an aggregate level. In reality companies have multiple CODPs. Main underlying factors of this diversity are the existence of different CODPs per individual product or product-market combination, per product component, per level of customer commitment (e.g. contracts versus specific call-offs), and per interface in the chain network (consumer-to-business orders and different business-to-business orders).

Taking these different dimensions of CODP diversity into account will result in many possible CODP positions and consequently in many possible chain network configurations. In responsive demand-driven chain networks, companies must be able to take part in different of these configurations concurrently in order to deliver customer or customer segment specific products. Further, they must be able to switch fast to new configurations in order to fulfill new or adjusted customer requirements rapidly. Process models are an important mean to keep this complexity manageable, whereas they enable clear and precise representation of the activities and interactions within and between all relevant configurations.

However, how to deal with the CODP diversity has received little attention in the literature so far. Several authors addressed complexity issues behind the generic CODP concept (e.g. Giesberts and Tang 1992; Trienekens 1999; Van der Vorst 2000; van Donk 2001; Wikner and Rudberg 2005), but is not yet developed it into concrete process designs.

The main objective of the paper is to model processes of demand-driven chain networks on basis of multiple CODPs. Therefore in section 2 the main dimensions of multiple CODP are modeled based on literature study. Next in section 3 these multiple CODPs are illustrated by a case study in the Dutch dairy industry based indepth interviews with logistic and ICT experts in The Netherlands. The paper ends in section 4 with a discussion and conclusions. 


\section{Modeling multiple CODPs}

As stated in the introduction, the widely accepted logistical typology based on different CODP positions of is on too aggregated level to be useful in process design. In this section four main underlying factors of CODP-diversity in practice (as addressed in literature, see mentioned references) are elaborated in order to make the CODP suitable for design of demand-driven chain networks. This is done by adding each dimension to a base-line model of the CODP-concept (see figure 1). At this, we define an order as an agreement between customer and supplier on the products to be delivered, the amount, price, time and place (all customer commitment information). This implies that contracts are viewed as orders. Demand forecast information is all information about future orders that is used for planning.

The distinguished dimensions are the existence of different CODPs per:

1 Product or product-market combination;

2 Product component;

3 Level of customer commitment;

4 Interface in the chain network.

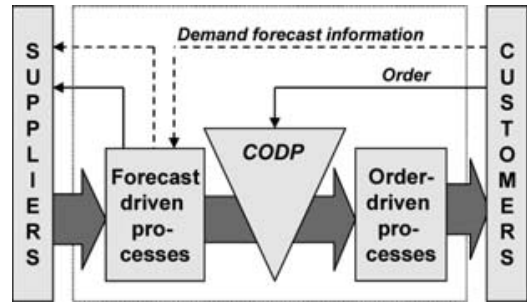

Fig. 1. Baseline CODP model

\section{Product or product-market combination}

Particularly in demand-driven chain networks, customers have their specific requirements to the products to be delivered. Within one company, this can result in different CODP positions for specific products or product-market combinations (figure 2). For example: companies can assemble products on customer order, while the remaining production capacity is used to make standard products on stock. Or the other way around: products with a stable baseline demand are produced on forecast, while products with a surge demand (e.g. in cases of sales promotions) are produced on customer

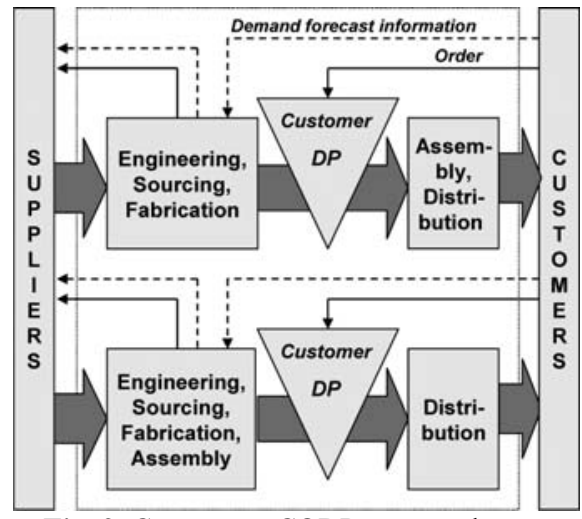

Fig. 2. Concurrent CODPs per product or product-market combination order. In literature this is often addressed, among others by Giesberts and Van der Tang (1992), Van der Vorst (2000), Christopher and Towill (2001), Van Donk (2001), Aitken et al. (2005) and Holweg (2005). 


\section{Product component}

The extent to what products are customized can vary much within the structure of a certain product per component (Giesberts and Tang 1992). For example: in assembly processes, often mostly standard components are used (ATO), while the components where customization adds most customer value are produced (MTS) or even engineered

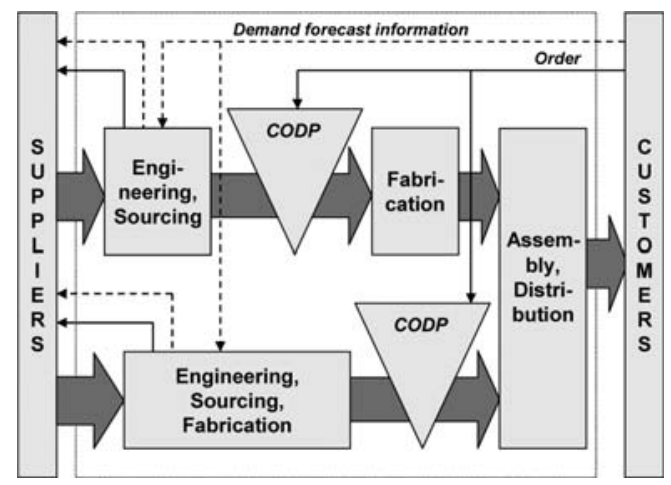

Fig. 3. Multiple CODPs per product component (ETO) on specific customer order. This results in hybrid situations with more CODPs for one product (see figure 3).

\section{Level of customer commitment}

An order is an agreement between customer and supplier on the product to be delivered (including packaging and added services), the amount, price, time and place. However, for many companies these different aspects are not agreed in one

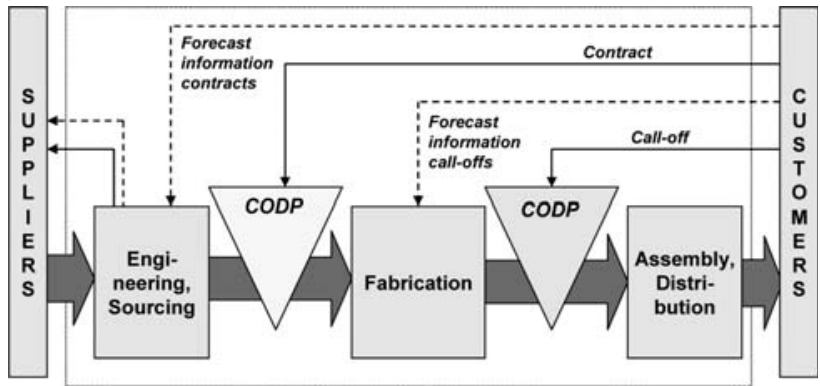

Fig. 4. Multiple CODPs per level of customer commitment order, but partly in contractual arrangements for more transactions. For example: in an annual contract the price, product attributes and minimal amount is specified, while time and actual amount is determined by specific call-offs. This results in a (sequential) range of possible CODP positions (Wikner and Rudberg 2005), at least one at contract conclusion and at calling-off (see figure 4).

\section{Interface in the chain network}

In literature the CODP-concept is often applied on supply chain networks without making clear the difference between consumer orders and the varied orders in the network of collaborating chain partners. Due to this diffusion, it is suggested that there is only one CODP per chain network. However, in realty there exists a CODP 
for each collaboration interface (Trienekens 1999), starting with the consumer order and working backward to business -to-business orders (see figure 5).

For the design of demand-driven chain processes, these dimensions have to be modeled together in coherence. This results in many possible chain network configurations with many different positions of CODPs.

\section{Dairy case}

Above four basic CODP dimensions are modeled in general. In this section we illustrate these multiple CODPs by a case study in dairy. In the study, the dairy processing industry was the focal actor in the chain network, while The Netherlands was the focal country. The case study was based on structured interviews with 15 dairy logistic and ICT experts (13 managers of different dairy processing companies and retailers, 2 consultants) and additional desk research.

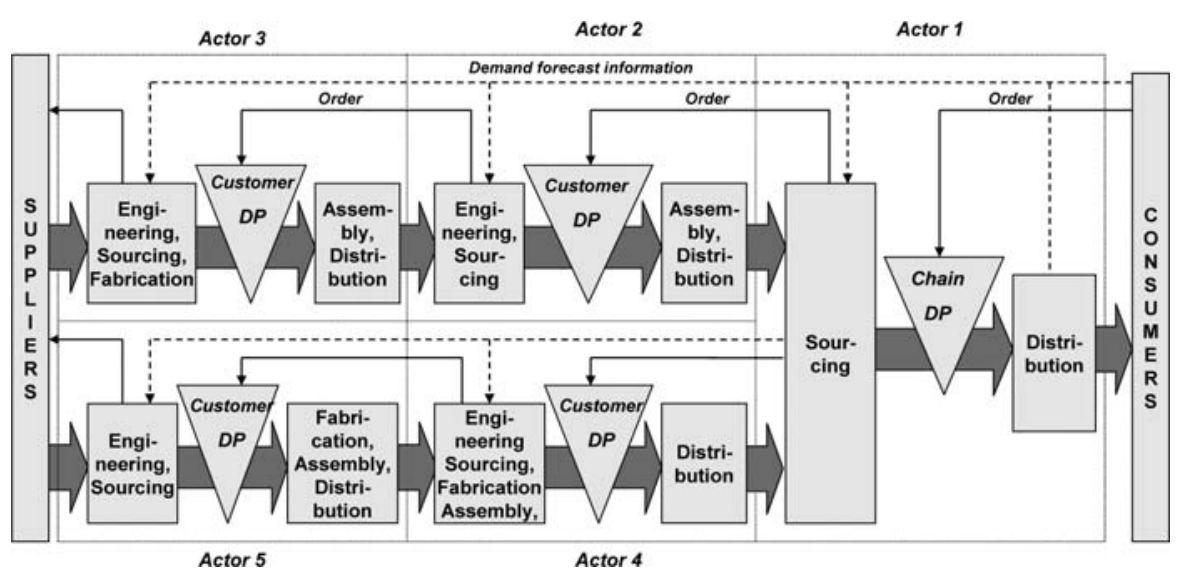

Fig. 5. Multiple CODPs per interface in the chain network

In the case study we investigated the current state in dairy industry according to market and performance requirements, network structure, processes, control systems and information technology (based on the chain framework of Van der Vorst et al. 2005, adapted from Lambert and Cooper 2000). Below we give a summarized overview of the results, focusing on the positions of multiple CODPs.

\section{Market and performance requirements}

The dairy industry is characterized by two main product categories: consumer and industrial products.

Main consumer products are fresh products (consumption milk, drinks, and desserts), cheese and butter. In the supermarkets these products belong to the basic assortment. Therefore, availability is very important. Further, shelf life is dominating the retail requirements of fresh products. In order to prevent stock outs and decay 
(resulting in obsolete inventory or forced markdowns), products are replenished frequently with short delivery times and high delivery reliability. Sometimes the supplier is responsible for replenishment of fresh dairy products (Vendor Managed Inventory).

Main industrial products are ingredients, mostly in the form of powders, for particularly the pharmaceutical, feed and food industry (including baby food, bakery ingredients, ice creams, cream liqueurs, food supplements and special diet food). There are two different markets of industrial ingredients: bulk delivery for the world market and specialties for specific customers, in close cooperation as per unique contracts. For bulk delivery the focus is on price and homogenous quality. For specialties the focus is on flexibility and specific quality features.

\section{Network structure and processes}

In 2005, in The Netherlands almost 11 million tons of milk were produced at about 25.000 farms (Silvis and De Bont 2006). Virtually all milk was delivered to one of the 13 dairy processing organizations, which processed the milk in a total of 55 factories. The processed milk is exported to a large extent. The Netherlands is a major exporter of dairy products to other EU member states, particular in cheese (Silvis and De Bont 2006).

Two international cooperatives -Campina and Friesland Foods- are responsible for processing more than $80 \%$ of all the country's milk. The cooperatives are obliged to take all supplied milk of their member farmers. The overall amount of production is fixed in quota by EU market regulations.

The dairy processing companies transform the supplied milk into a broad range of products in different shelf life categories with different production lead times for different customer segments. The production processes are capital intensive and include milk collection from the farmers, pasteurization and standardization, drying into milk powder (for non-perishables), refinement into different components, processing these components into end products, and packaging. The flows into different end-products are highly interdependent. By-products of one end product are input of other products. For example: production of cheese results in whey that is processed into different industrial ingredients. Further, a specific characteristic of cheese production is the ripening process, during which weight is being reduced, while value is being increased.

\section{Multiple CODPs in dairy}

Important factors impacting the CODPs positions in dairy are the broad range of end products for different markets and with different levels of decay, high interdependencies between product flows, high volume production, low volume flexibility (more or less fixed milk supply and capital intensive production). Due to these characteristics much diversity of CODP was found in the case study:

1. CODPs per product or product-market combination. Within the two main product categories, different CODP positions are found per specific customer segment. For fresh consumer products, including butter, Make to Stock (MTS) is most common, but also forms of Assemble to Order (ATO) exist. For example: specific health drinks that are produced on order from high concentrated liquids (thinning and adding specific ingredients). Most common in cheese is production of whole cheeses on forecast, whereas cutting and 
packing is done on customer order. In the industrial ingredients segment, specialties are produced and sometimes even engineered on customer order. The remaining production capacity is used for bulk production.

2. CODPs per product component. A typical example of different CODPs per component is cheese production. Cheese is mostly cut and packaged on customer order, but on basis of standard package material. Another example is the production of specialty ingredients, whereas both standard and customerspecific powders are blended on customer-order.

3. CODPs per level of customer commitment. Contracts are widespread in dairy industry. Processing companies have long-term contracts with farmers (either as member of the cooperative or regular contracts), in which milk quality requirements and maximal quantities (including sanctions and bonuses) are specified (price is variable). Also transactions with suppliers of packaging and additional ingredients are based on contracts. Further, processing companies have several types of contracts with their customers, both of industrial ingredients and consumer products. In the consumer product segment, sometimes Vendor Managed Inventory contracts are found. At this, call-offs are not triggered by customers, but replenishment is the supplier responsibility.

4. CODP per interface in the chain network. Viewed from the processing industry as focal company, main actors of the dairy chain network are supermarkets, their purchasing companies or wholesalers (including DC's), second order industry, farmers and suppliers of additional ingredients and packaging. Each interface has its own CODPs.

Taking these dimensions into account shows that many chain network configurations exists in dairy. Figure 6 illustrates a dairy configuration that covers the different dimensions of CODP diversity.

The figure depicts basic processes of retailers, first order processing industry (focal actor) and farmers. It represents three different customer segments, with each multiple CODPs. In the middle of the diagram, production of fresh products is illustrated. Here, only distribution is on retail order. Up there, production and distribution of cheese are depicted. Here different CODPs exist for packaging and cheese cutting. Below the delivery of customer-specific industrial ingredients based on contracts is shown. 


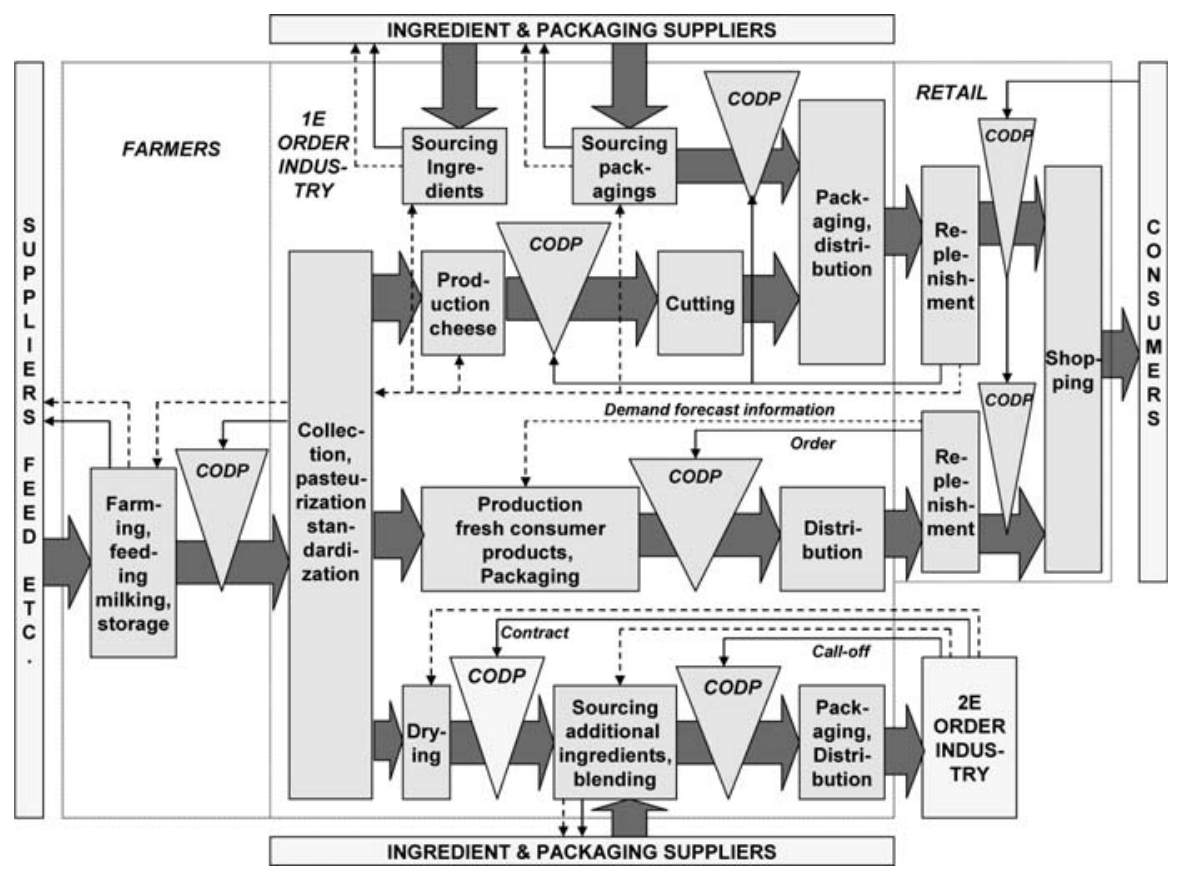

Fig. 6. Example of a chain network configuration with multiple CODPs in dairy

\section{Discussion and conclusions}

In this paper the generic CODP concept is expanded by modeling four main underlying factors of CODP diversity: the existence of different CODPs per product or product-market combination, per product component, per level of customer commitment (e.g. contracts versus specific call-offs), and per interface in the chain network (consumer-to-business orders and different business-to-business orders).

In the case study each dimension of CODP diversity was found in dairy. Many different CODP positions exist concurrently, even in this industry that is high volume, capital intensive, highly regulated and in which products decay.

This shows that taking the different dimensions of CODP diversity into account results in many concurrent chain network configurations. Detailed process models are an important mean to make this complexity manageable. Companies can develop their process models from scratch. However, disadvantages of this approach are high costs of the design process and long lead-times, which hinder rapid process (re)configuration and thus flexibility. An alternative approach is to start with predefined business process models that capture recommended practices and experiences of other companies. Such predefined models are called reference models.

The multiple CODP models as described in this paper provide the basic setup of a reference-process model for demand-driven chain networks. Further research is 
recommended to develop this into a formalized model that incorporates detailed implementation knowledge of different industries.

\section{References}

1. Aitken, J., P. Childerhouse, M. Christopher and D. Towill, 2005. Designing and Managing Multiple Pipelines. Journal of Business Logistics. 26, 2, 73-95.

2. Christopher, M. and D. Towill, 2001. An integrated model for the design of agile supply chains. International Journal of Physical Distribution \& Logistics Management. 31, 4, 235-247.

3. Giesberts, P. M. J. and L. v. d. Tang, 1992. Dynamics of the customer order decoupling point: impact on information systems for production control. Production Planning \& Control. 3, 3, 300-313.

4. Hoekstra, S. J. and J. M. Romme, 1992. Integral Logistic Structures: Developing Customer-oriented Goods Flow. McGraw Hill, London.

5. Holweg, M., 2005. The three dimensions of responsiveness. International Journal of Operations \& Production Management. 25, 7, 603-622.

6. Lambert, D. M. and M. C. Cooper, 2000. Issues in supply chain management. Industrial Marketing Management. 29, 1, 65-83.

7. Mather, H., 1988. Competitive Manufacturing. Prentice-Hall, Englewood Cliffs, NJ.

8. Naylor, B., M. M. Naim and D. Berry, 1999. Leagility: interfacing the lean and agile manufacturing paradigm in the total supply chain. International Journal of Production Economics. 62, 107-118.

9. Olhager, J., 2003. Strategic positioning of the order penetration point. International Journal of Production Economics. 85, 3, 319.

10. Silvis, H. and K. de Bont, 2006. Prospects for the agricultural sector in The Netherlands. The Hague, Ministry of Agriculture, Nature and Food Quality.

11. Trienekens, J. H., 1999. Management of processes in chains: A research framework, PHD-thesis, Wageningen University.

12. Van der Vorst, J., A. Beulens and P. v. Beek, 2005. Innovations in Logistics and ICT in Food Supply Chain Networks. In: Innovations in agri-food systems: Product quality and consumer acceptance. W. M. F. Jongen and M. T. G. Meulenberg. Wageningen Academic Publishers. 
13. Van der Vorst, J. G. A. J., 2000. Effective Food Supply Chains: Generating, modelling and evaluating supply chain scenarios. PHD-thesis, Wageningen University.

14. Van Donk, D. P., 2001. Make to stock or make to order: The decoupling point in the food processing industries. International Journal of Production Economics. 69, 3, 297-306.

15. Wikner, J. and M. Rudberg, 2005. Introducing a customer order decoupling zone in logistics decision-making. International Journal of Logistics. 8, 3, 211 - 224. 